\title{
De ciudad-huerta a pueblo boutique. Turismo y transformaciones materiales en Purmamarca ${ }^{1}$
}

\author{
Constanza Tommei ${ }^{2}$ y Alejandro Benedetti ${ }^{3}$
}

\begin{abstract}
RESUMEN
Con el inicio del siglo XXI se asistió a una profunda transformación del pueblo andino de Purmamarca (provincia de Jujuy, República Argentina). Hasta la década de 1980, el lugar tenía el carácter de una "ciudad-huerta" como fue definido en una ordenanza por el gobierno local. Diferentes acontecimientos acaecidos en la década de 1990 permitieron que el lugar se fuera transformando en un importante destino turístico de la Argentina. Así, aquel pequeño pueblo rural del interior jujeño fue cambiando, tanto en sus prácticas materiales como simbólicas. En este artículo prestaremos atención a aquellas modificaciones ocurridas en el plano material. Veremos cómo se expandió y densificó el pueblo de Purmamarca y cómo se modificó la traza histórica. También describiremos los nuevos usos del suelo que fueron apareciendo y prestaremos particular atención al surgimiento de una concepción boutique, aplicada tanto a la estética edilicia como al funcionamiento de actividades, no solo turísticas, sino, también, de servicios públicos. Finalmente, haremos una breve referencia al surgimiento de un pueblo-dormitorio, que fue una emergente del proceso reseñado. El material empírico utilizado en este artículo surge de la sistematización de fuentes oficiales, de análisis de descripciones realizadas del lugar en diferentes momentos históricos y de registros propios realizados en el terreno.
\end{abstract}

Palabras clave: Turistificación, boutique, espacio material, Purmamarca, Jujuy.

\begin{abstract}
With the beginning of the 21 st century, the Andean town of Purmamarca (Province of Jujuy, Argentina) has undergone a profound transformation. Until the 1980s, the area had the character of a "garden city", as defined in a local government ordinance. Several events in the 1990s allowed the area to be transformed into a major tourist destination in Argentina. Thus, this small rural town in Jujuy began to change, both in its material and symbolic practices. In this article we will focus on those changes that occurred in the material plane. We will see how the village of Purmamarca expanded and increased in density, and how its historical footprint was modified. We will also describe the new land uses that appeared and we will pay special attention to the emergence of a boutique concept, applied to both the construction industry and aesthetic activities, not only in tourism ventures, but also in public services. Finally, we will make a brief reference to the emergence of a bedroom-town, which was the result of the processes outlined herein. The empirical material used in this article comes from the systematization of official sources, analysis of site descriptions made at various historical moments and our own field records.
\end{abstract}

Key words: Touristification, boutique, material space, Purmamarca, Jujuy.

1 Artículo recibido el 23 de abril de 2013, aceptado el 12 de agosto de 2013 y corregido el 25 de noviembre de 2013.
2 CONICET/Universidad de Buenos Aires (Argentina). E-mail: ctommei@gmail.com

3 CONICET/Universidad de Buenos Aires (Argentina). E-mail: alejandrobenedetti@conicet.gov.ar 
Purmamarca es un poblado emplazado en la provincia de Jujuy, en el noroeste argentino, cuya arquitectura tradicional se articulaba con el perfil socioeconómico agropastoril de su población. A lo largo de las décadas de 1990 y 2000 esa cultura material se transformó de manera considerable, siendo progresivamente reemplazada por otra de tipo boutique, donde se amalgamaron elementos estéticos, funcionales y constructivos tradicionales, de tipo rural y andino, con desarrollos arquitectónicos que tienen una fuerte impronta urbana y turística. El lugar se adaptó a los parámetros estéticos, preferencias de consumo y prácticas recreativas de turistas procedentes, en gran parte, de la capital del país y del extranjero, habituados a consumir bienes y servicios exclusivos, algo onerosos y de alta gama. El tema de este artículo es la transformación material de Purmamarca, que había sido designada por las autoridades locales como "ciudad huerta" (Ordenanza Municipal $N^{\circ}$ 006, año 1971), en un lugar boutique, como se lo menciona en diferentes medios de comunicación. Esta transformación está fuertemente vinculada a la emergencia de la actividad turística impulsada fundamentalmente por actores extralocales.

Los lugares de destino turístico se van construyendo como resultado de diferentes prácticas materiales y simbólicas de la sociedad, mediante las cuales se van destacando y poniendo en valor ciertos elementos, procesos o atributos que allí se encuentran. Se trata de un proceso de construcción del lugar como destino turístico o, utilizando un neologismo, de turistificación (Navarro Floria y Vejsberg, 2009). La turistificación es una determinada asignación social que reciben los lugares, a partir del cual se le otorga una valoración positiva que concita un interés por conocerlo y utilizarlo (BertonceIlo, 2008). Esto involucra una gran variedad de situaciones: la activación patrimonial, la construcción de un imaginario paisajístico y la producción y difusión de ideas sobre el lugar, generando el deseo de realizar un viaje hasta allí. El proceso de construcción de Purmamarca en el plano simbólico, como lugar de interés turístico, se inició en la década de 1940, momento en que su iglesia fue declarada Monumento Histórico Nacional, aunque recién se potenció en la década de 1980 y, claramente, se aceleró en las décadas siguientes. En un trabajo anterior (Tommei y Benedetti, 2012) analizamos, a partir de diferentes dispositivos discursivos y gráficos -manuales escolares, guías turísticas, relatos de viaje y literatura- de qué manera se fue canonizando al Ilamado Cerro de Siete Colores allí situado, como paisaje emblemático, no solo de Purmamarca, sino también de Jujuy y de la Argentina, a través de infinidad de medios de comunicación. Esto fue potenciado en 2003 cuando la Quebrada de Humahuaca, región que incluye a este pueblo, fue declarada Patrimonio de la Humanidad en la categoría paisaje cultural y natural. Este proceso de activación del lugar en el plano simbólico se articula con otro en el plano material.

Dentro de los procesos culturales, los acondicionamientos materiales tienen una gran importancia, aunque no son siempre tenidos en cuenta. En este sentido, los cambios materiales de los lugares en función de la lógica turística pueden ser un importante insumo de análisis para comprender la transformación de un sitio devenido en destino turístico. La adaptación de la infraestructura, la redefinición estética de las edificaciones, la mejora en las condiciones de accesibilidad, la modificación en la traza, la refuncionalización de las calles, los cambios en los usos del suelo y el desarrollo de equipamiento hotelero y comercial son prácticas materiales que contribuyen a la valorización de los lugares en su condición de atractivos turísticos. En este trabajo, entonces, nos centraremos en el componente material del proceso de turistificación de Purmamarca.

Este artículo se enmarca en investigaciones más amplias que se proponen indagar sobre los cambios y continuidades en el espacio socialmente construido de Purmamarca, ligadas al desarrollo del turismo, y sobre las transformaciones de las espacialidades andinas en el extremo noroeste argentino. Aquí se presentan resultados que surgen de plantearse como objetivo específico identificar y describir las prácticas materiales mediante las cuales Purmamarca se transformó, en el marco de los episodios reseñados, en un importante atractivo turístico de escala regional, nacional e internacional. La base empírica se nutre de diferentes relevamientos efectuados en el terreno, de la sistematización de fuentes de información estadística y oficial y del análisis 
de diversas descripciones realizadas sobre el lugar. Pondremos foco en cinco cursos de acción que, consideramos, se sucedieron simultáneamente y que son solidarios entre sí: 1. la expansión del área construida y la densificación edilicia; 2. los cambios en la traza histórica; 3. los cambios en los usos del suelo; 4. la renovación arquitectónica; y, 5. el surgimiento de una nueva área urbanizada, denominada Chalala, cerca de dos $\mathrm{km}$ del pueblo de Purmamarca.

\section{Prácticas materiales en la turistificación de Purmamarca}

Partimos de la constatación de que Purmamarca es un lugar devenido en atractivo turístico. Allí, el acondicionamiento material para facilitar la visita turística se inició en la década de 1970 con la construcción de la ruta provincial 16 (hoy ruta nacional 52 -en adelante, RP y RN) que permitió una mejor accesibilidad desde la RN 9, ruta que atraviesa toda la provincia de Jujuy y que la conecta con Buenos Aires. Entre las décadas de 1970 y 1990 se establecieron, lentamente, algunos servicios mínimos orientados a los turistas que pasaban por allí, quienes generalmente hacían viajes guiados en circuitos por la Quebrada de Humahuaca, organizados por empresas salteñas. A partir de la crisis de 2001 en la Argentina se incrementó el turismo interno, siendo esa región uno de los destinos que más crecieron. La Quebrada de Humahuaca adquirió mayor visibilidad como destino turístico a partir de la patrimonialización, en el año 2003. Tras importantes gestiones gubernamentales, la UNESCO declaró Patrimonio de la Humanidad a la Quebrada de Humahuaca, bajo la categoría de Paisaje Cultural, que se lo define como aquel que "incluye una diversidad de manifestaciones de la interacción entre el hombre y su ambiente natural" (Rössler, 1998:50). En este contexto, al cabo de unos pocos años, Purmamarca se transformó en un atractivo turístico de escalas regional, nacional e internacional. Si en 2001, la oferta de servicios turísticos era escasa, al poco tiempo comenzó a multiplicarse sostenidamente, proceso que, pareciera, todavía no ha alcanzado su fin. Ahora, los visitantes permanecen por períodos prolongados y esto fue posible gracias a la instalación de servicios hoteleros y gas- tronómicos que antes no existían, entre otras prestaciones (para la consideración de estas transformaciones a escala regional remitimos a la producción de Claudia Troncoso (2009a, 2009b y 2010).

\section{Extensión espacial y densificación edilicia}

El emplazamiento de Purmamarca se remonta a finales del siglo $\mathrm{XVI}^{4}$. Su función era concentrar a la población de la zona en torno a la capilla. Fue el último de los pueblos de indio creados en la región, a una legua al oeste del encuentro de las quebradas de los ríos Purmamarca y Grande de Humahuaca. La zona, de todas formas, ya estaba poblada en el período prehispánico (Sica, 2006). Por allí pasaba un camino de arriería secundario, en dirección este-oeste, que conectaba la quebrada del río Grande con las tierras altoandinas. Desde fines del siglo XIX, en sentido contrario, fue zona de paso de los minerales extraídos en la zona de Salinas Grandes, enviados hacia el puerto de Rosario. Esto motivó el establecimiento de una estación ferroviaria hacia 1907, distante a 4 kilómetros al este del poblado de Purmamarca. Por esta razón, permaneció alejado del principal camino que vinculaba a la capital con el norte de la provincia, el camino de la Quebrada de

\footnotetext{
4 En la literatura toponímica regional a Purmamarca se le adjudican diferentes significados. En algunos estudios se lo define como en voz Quichua como "Pueblo del puma" o "Pueblo de León", pero, si se deriva de "p'uhru-ma-marca", significaría "hoyada, hondada o lugar cóncavo donde hay agua" (Fidalgo, 1965:18). Además, encontramos que se lo ha traducido como "pueblo rojo"; Purma se relaciona con el "rojo de sus montañas" del Inca peruano (Conozca Jujuy, en Burgos, 1960: 35). Hoy se acostumbra a mencionar en muchos documentos que su nombre deriva de las palabras aymara "purma", campo que no se sembró, desierto; y "marca", pueblo, interpretándose entonces como "pueblo en el desierto" y más ampliamente como "pueblo de tierra virgen" (Paleari 1981:132). Guzmán (2004), a partir de las investigaciones realizadas por Sandra Sánchez, informa que en la documentación del siglo XVI y XVII también aparecía como Purumamarca, Pumamarca y Plumamarca. Todavía en el siglo XIX se intercambiaba con otras formas de escritura, como Pulmamarca (Cf. Bertrand, 1885). Considerando que este topónimo también se encuentra en la región de Ollantaytambo, en Perú, Sánchez (1996:56 en Guzmán, 2004: 81) considera que significa, "la puerta, el acceso o el camino a los despoblados de la puna".
} 
Figura $\mathrm{N}^{\circ} 1$

Localización de Purmamarca en Jujuy, República Argentina

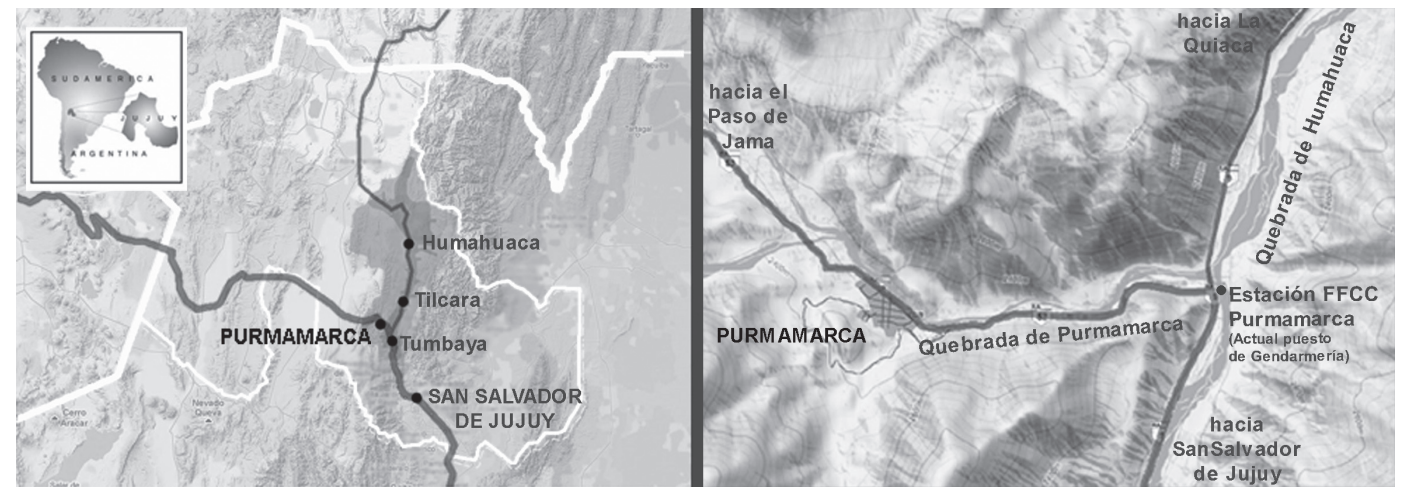

Fuente: Elaboración propia en base a Google Maps y folleto turístico de la provincia de Jujuy.

Humahuaca, que bordeaba al río Grande de Jujuy (Benedetti, 2003; 2006) (Figura N¹).

Este sitio se emplazó en un valle estrecho, donde la población desarrollaba una economía agropastoril de baja intensidad. La localidad no experimentó un crecimiento demográfico a lo largo del siglo XX: mientras que el censo de 1895 computó para Purmamarca 545 habitantes, el de 1970 registró 269 habitantes y el de 2001510 habitantes. En la actualidad la población Ilega a 891 habitantes (INDEC, 2010), sin contabilizar a quienes trabajan en el pueblo pero viven a dos kilómetros, en un paraje que surgió en 2003 Ilamado Chalala donde residen, según estimaciones propias dado que no ha sido identificado por el último censo, unas 200 personas (Cuadro $N^{\circ} 1$ ). Volveremos a este caso más adelante.

Los terrenos donde se estableció el casco urbano, que tienen una extensión de cerca de 13 hectáreas, se encuentran rodeados por importantes barreras físicas, lo que dificulta la expansión edilicia más allá de los terrenos existentes. Al norte se encuentra el río Purmamarca y el cerro Morado; al este, el arroyo y quebrada de Tumbaya; y, al sur y al oeste, se ubican el cerro de Siete Colores y el cerro Verde (Figura $\mathrm{N}^{\circ} 2$ ).

Durante la segunda mitad del siglo XX es probable que la extensión y la densificación edilicia en Purmamarca hayan permanecido sin cambios sustantivos, lo que comenzó a producirse durante la década de 1990. Esto lo podemos constatar a partir de la comparación de tres mapas, de los años 1964, 1991 y 2009 (Figura $N^{\circ} 3$ ). Según un registro realizado en la década de 1960, por entonces Purmamarca solo tenía 25 familias que habitaban en forma permanente el lugar. Había 8 viviendas que eran de residencia temporaria y otras 17 que estaban en ruinas o deshabilitadas. Las viviendas estaban implantadas en solares que oscilaban entre los 500 y los 2.000 $\mathrm{m}^{2}$, definidos con gran libertad y variedad, dentro de las direcciones impuestas por las trazas generales. Los solares en explotación comprendían viviendas con patios, zonas de influencia de la vivienda con solados de tierra y terreno para cultivo y animales (Nicolini, 1964b). Entre los años 1964 y 1991, basándonos en el plano realizado por el arquitecto Nicolini (1964) y en el plano del Censo de 1991, se puede observar cierta continuidad. Una de las expansiones más significativas, en esos años, deriva de la construcción de "las 10 viviendas", que se encuentran al este de la aglomeración ${ }^{5}$, al pie de los cerros El Porito y del cerro de Siete Colores. Estas

\footnotetext{
5 En este artículo utilizaremos la categoría aglomeración para referir a una concentración espacial de calles y edificios. Remite al espacio material de un pueblo o de una ciudad. En la Argentina, el INDEC utiliza un criterio físico para la determinación censal de localidades. Definidas de esta forma, da cuenta de un espacio funcional, más allá de los límites administrativos que pueda atravesar.
} 
Cuadro $\mathrm{N}^{\circ} 1$.

Tamaño de la población de Purmamarca en diferentes relevamientos censales nacionales y otras fuentes, 1869-2001

\begin{tabular}{|c|c|c|c|}
\hline Año & $\begin{array}{c}\text { Habitantes } \\
\text { Purmamarca }\end{array}$ & Fuente & Observaciones \\
\hline 1869 & $\mathrm{~s} / \mathrm{d}$ & Censo nacional & $\begin{array}{l}\text { No se presenta información para la localidad de } \\
\text { Purmamarca, siendo la de Tumbaya de } 104 \text { habitan- } \\
\text { tes y } 1643 \text { el total del departamento de Tumbaya. }\end{array}$ \\
\hline 1895 & 545 & Censo nacional & \\
\hline 1937 & 1.380 & $\begin{array}{c}\text { Sánchez de } \\
\text { Bustamante } 1937\end{array}$ & $\begin{array}{l}\text { Purmamarca era uno de los cuatro lugares más po- } \\
\text { blados de la región. Probablemente en este cálculo } \\
\text { se incluyó a la población rural dispersa }\end{array}$ \\
\hline 1964 & 100 & Nicolini 1964 & $\begin{array}{l}\text { Los habitantes, según este autor, aumentan a } 150 \\
\text { en verano }\end{array}$ \\
\hline 1970 & 269 & Censo nacional & \\
\hline 1980 & 314 & Censo nacional & \\
\hline 1991 & 339 & Censo nacional & \\
\hline 2001 & 501 & Censo nacional & \\
\hline 2010 & 891 & INDEC & \\
\hline
\end{tabular}

Fuente: Elaboración propia, en base a las fuentes indicadas en el cuadro (3ra columna).

viviendas fueron realizadas como parte de un plan social financiado por el estado nacional, en el cual participó el municipio local en la toma de decisiones referidas a la implantación y diseño. Otro emprendimiento fue la subdivisión y cesión gratuita de lotes realizada por el estado provincial a diferentes familias que habitaban en Purmamarca, en "la costanera" (denominación local del espacio sobre la avenida San Martín; específicamente, se lotearon los terrenos que están sobre esa avenida entre la calle Belgrano y Pantaleón Cruz), al noroeste de la aglomeración.

El mayor cambio se puede verificar, con seguridad, entre los años 1991 y 2009, tanto en el área urbana como en las afueras, en los terrenos ubicados a ambos márgenes de la RN52. Comparando el plano redibujado a partir del plano del Censo de 1991 extraído de la sección "patrimonio arquitectónico y urbanístico" 6 elaborado para hacer el informe que luego fue entregado a la UNESCO para la postulación de la Quebrada como Patrimonio

\footnotetext{
6 Informe entregado en la Unidad de Gestión de la Quebrada de Humahuaca en el año 2010.
}

de la Humanidad y el realizado en base al relevamiento propio (Figura $N^{\circ} 3$ ), dentro del poblado se verifica crecimiento por (a) expansión de la mancha urbana, que se produjo hacia el oeste, hasta las estribaciones del cerro de Siete Colores -debido a las limitantes físicas antes mencionadas, en ese lapso solo ha incorporado cerca de seis manzanas a la traza histórica-; y, por (b) densificación del espacio construido -ya que se realizaron nuevas obras y se refuncionalizaron y modificaron otras antiguas-. Asimismo, se observa un mayor parcelado: el terreno se ha subdividido y, consecuentemente, los lotes son más pequeños, generándose nuevas construcciones allí donde antes había usos no residenciales. Concomitantemente, tendió a desaparecer la mayoría de los cultivos que existían en el interior del poblado.

Más allá de los límites impuestos por las barreras físicas, tras la mejora de la RN 52 , el aumento en la demanda de suelo y el incremento del precio de los lotes libres -debido al crecimiento poblacional y turístico-, surgieron nuevas formas de expansión urbana por fuera del poblado. Esto se pueden observar en el plano realizado en base a rele- 
Figura $\mathrm{N}^{\circ} 2$

Purmamarca. Principales elementos que definen la aglomeración, año 2010

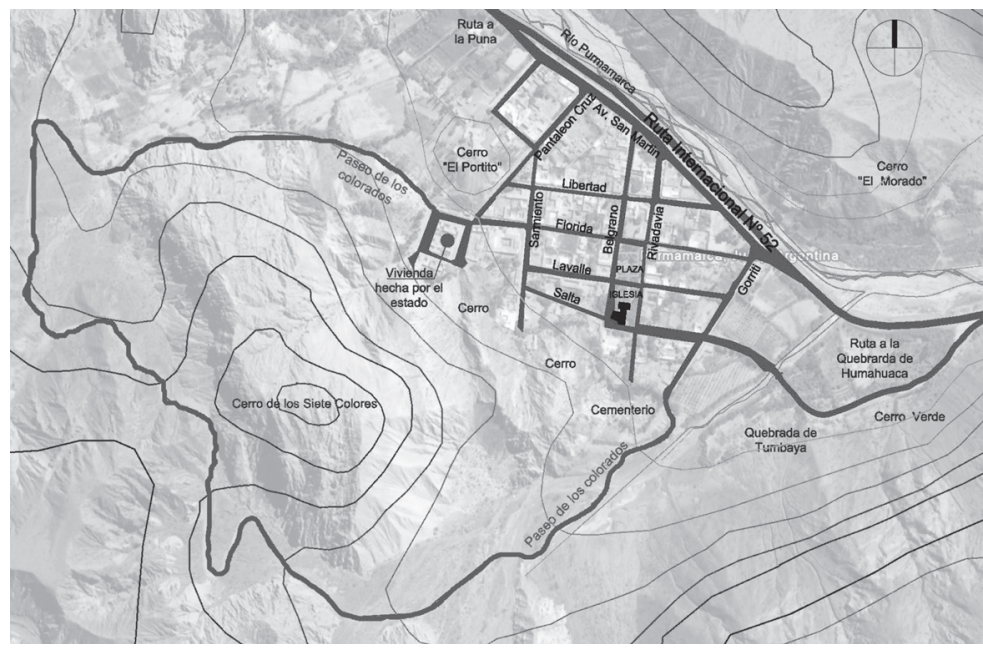

Fuente: Elaboración propia sobre la base de Google Earth.

vamientos propios (2009 y 2011) y al plano otorgado por el departamento de Catastro de la provincia de Jujuy, correspondiente al año 2009 (Figura $N^{\circ} 4$ ). Con este material pudimos identificar dos procesos de crecimiento más. Por un lado (c) la expansión y prolongación del área construida en forma paralela a la RN52, en terrenos que tenían usos exclusivamente agropecuarios. Ahora, se destinan a albergar nuevas funciones: viviendas $y$ establecimientos turísticos. Otra alternativa fue (d) la relocalización de muchas personas en un nuevo loteo, donde se formó el paraje
Chalala, ubicado a aproximadamente dos kilómetros al oeste del pueblo, sobre un espacio relativamente llano que se forma en una quebrada transversal a la de Purmamarca.

En síntesis, entre 1991 y 2009, Purmamarca experimentó un importante crecimiento, el cual ocurrió, simultáneamente, de cuatro formas: por expansión de la mancha urbana, por densificación, por crecimiento lineal paralelo a la RN52 y por el surgimiento de un nuevo loteo. Este crecimiento provocó un cambio radical del perfil arquitectónico local.

Figura $\mathrm{N}^{\circ} 3$

Purmamarca. Expansión de la aglomeración. Años 1964, 1991 y 2009.
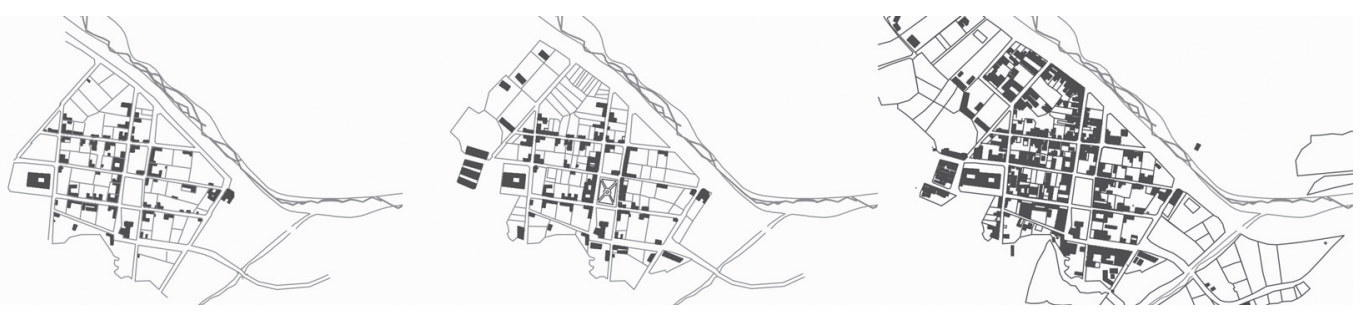

Fuente: Elaboración propia, a partir de los planos de: Nicolini, 1964b; Censo de 1991; plano de la oficina de Catastro de la provincia de Jujuy de 2009 y relevamiento propio, 2009. 
Figura $N^{\circ} 4$

Purmamarca y Chalala. Plano de las aglomeraciones y zonas aledañas. Clasificación de usos del suelo. Año 2011

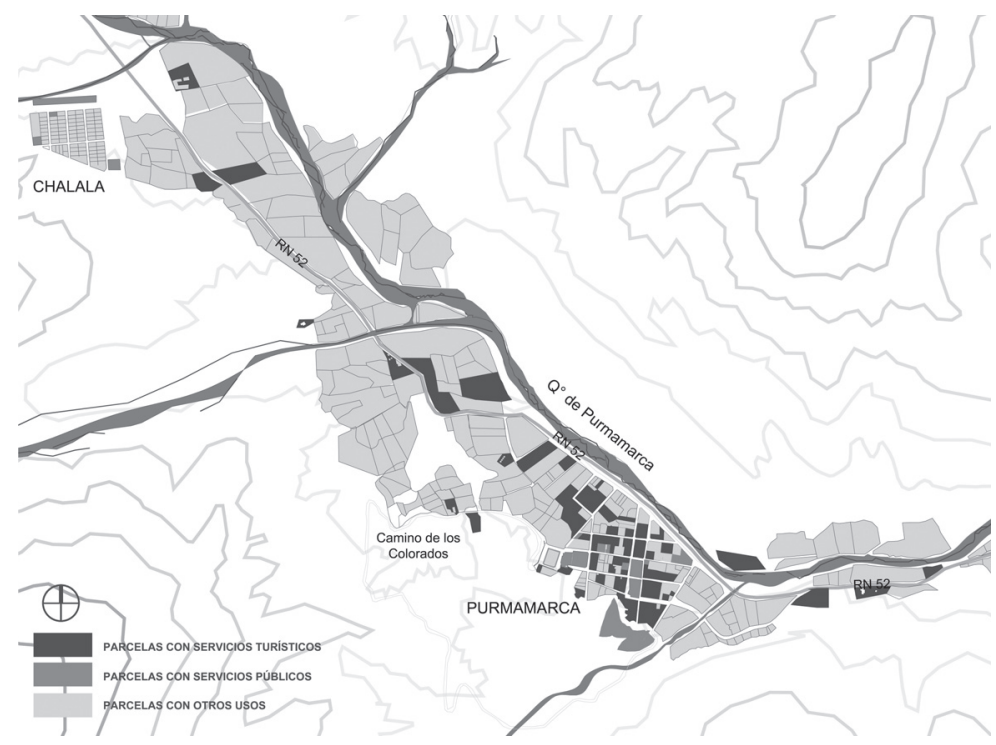

Fuente: Elaboración propia, en base al relevamiento propio, 2009 y 2011, y al catastro de Jujuy, 2009.

\section{Cambios en la traza histórica}

Son cinco los elementos que, históricamente, fueron definiendo la traza de Purmamarca, los cuales se analizarán seguidamente, evaluando su situación en el presente.

\section{La capilla}

Se estima que la capilla, consagrada a Santa Rosa de Lima de Purmamarca, data del siglo XVII. Este edificio fijó el emplazamiento del "pueblo de indios" según indicaban las leyes de indias (Nicolini, 1964: 28) y es el punto en torno al cual se fue formando el amanzanamiento. En los pueblos de indios, la iglesia, además de ser el núcleo generador de la estructura formal, ocupaba un lugar alto y dominante (Nicolini, 1993), como en este caso, cuya entrada mira hacia el norte, hacia donde está el río Purmamarca. Este edificio mantiene, en la actualidad, su posición central: todo caminante lo ve fácilmente al recorrer la localidad, aunque cada vez más las nuevas construcciones le han disputado su situación de privilegio e importancia. Asimis- mo, su telón de fondo dejó de ser los cerros, que contrastaban con el color blanco de sus muros. Actualmente, además de notarse un importante crecimiento de la vegetación que rodea la iglesia, se interponen entre esta y los cerros una sucesión de construcciones, tanto de viviendas como de equipamiento turístico (Figura $\mathrm{N}^{\circ}$ 5).

\section{La organización catastral}

A mediados del siglo XIX se llevó a cabo el amojonamiento y deslinde del pueblo. Es posible que en ese momento se hayan alineado las calles y definido las parcelas. Al menos las dos calles oblicuas que limitan el pueblo al este y al oeste fueron trazadas entonces (Nicolini, 1993). La calle Salta, detrás de la iglesia, posee un trazado más irregular. Allí se sitúan los edificios y la arboleda más antigua. Muy probablemente haya sido esta la zona del asentamiento del pueblo viejo ( $\mathrm{Ni}$ colini, 1964a y 1964b). La traza original de Purmamarca tiene cierta ortogonalidad, con dirección norte-sur y este-oeste. Es un trazado rectilíneo irregular, con un relativo paralelis- 
Figura $N^{\circ} 5$

Iglesia de Purmamarca: telón de fondo y alrededores
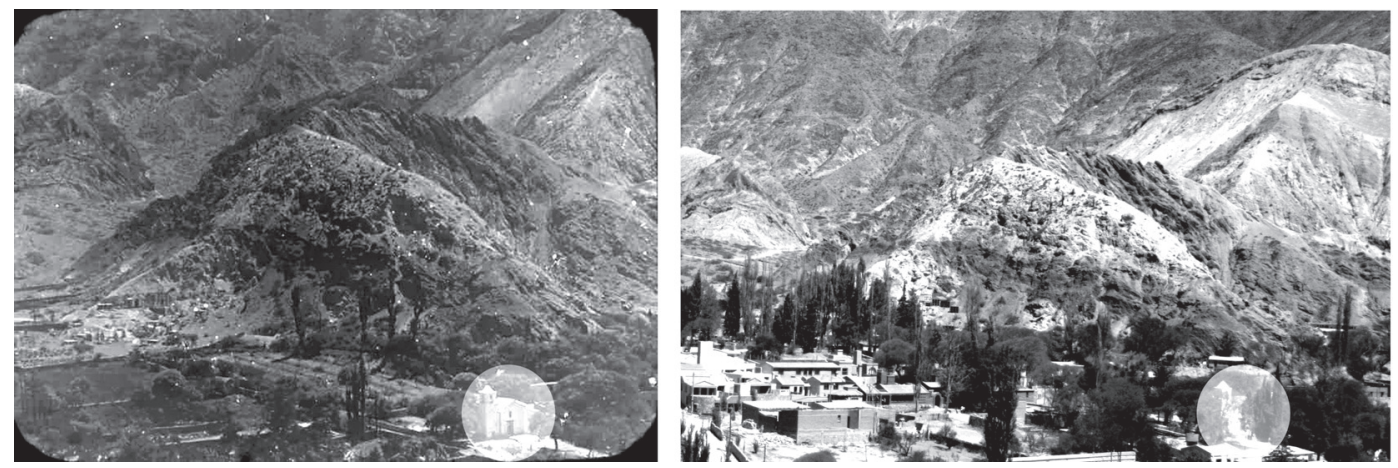

Fuentes: (Izquierda) Alberto Nicolini, década de 1960 (entregada por el autor) / (Derecha) Fotografía propia, septiembre 2009 .

mo entre las calles, con excepción de Gorriti y Pantaleón Cruz, trazadas en diagonal, sensiblemente paralelas entre ellas. Estas dos calles diagonales, que en la década de 1960 fueron identificadas como límites urbanos de Purmamarca (Nicolini, 1964b), hoy generan un quiebre en la trama urbana que continúa más allá de los límites del pasado (Figura $N^{\circ} 6$ ).

Figura $\mathrm{N}^{\circ} 6$

Expansión del área urbana más allá de la calle Pantaleón Cruz, límite identificado en la década de 1960. Vista desde el cerro El Porito hacia el norte del pueblo

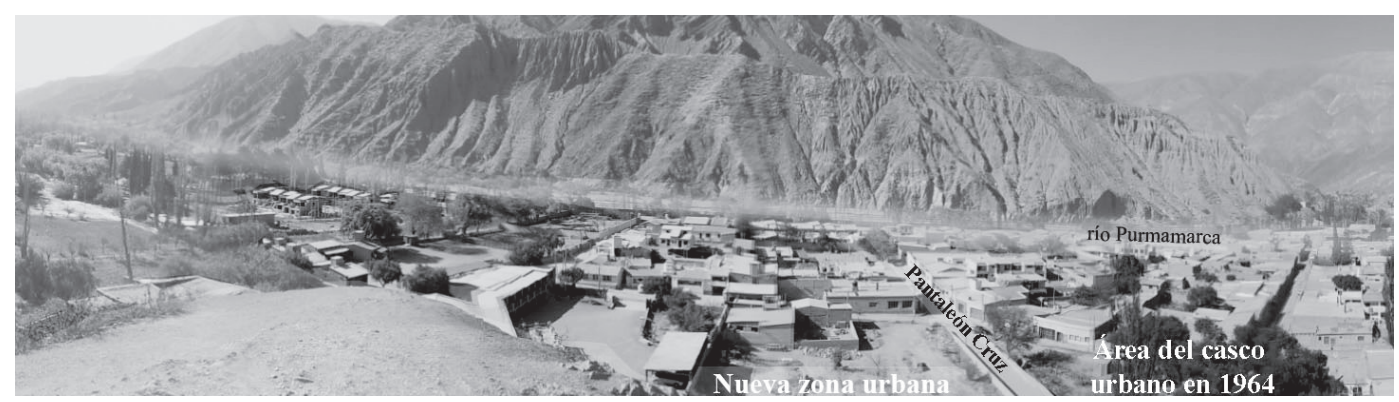

Fuentes: Elaboración propia en base a la imagen panorámica propia, 2012.

\section{Los edificios públicos}

En el año 1913 la Legislatura de la provincia de Jujuy sancionó la Ley № 227 por la cual dejaba creada la Comisión Municipal de Purmamarca en el Departamento de Tumbaya (Paleari, 1993). Un año después, se constituyó la primera Comisión Municipal de Purmamarca (Aban, 1990). En 1914 se establecieron el Juzgado de Paz y el Registro civil. Los edificios de estas instituciones fueron emplazados frente a la plaza en un lugar de privilegio y visibilidad, junto a la iglesia. En el lateral contrario ya estaba el "Cabildo de Purmamarca". Si bien esa particular construcción con características arquitectónicas de tipo cabildo no tenía una función institucional en el sentido colonial, fue un edificio estatal utilizado en varias ocasiones como alberge de las autoridades públicas. A finales del siglo XX se convirtió en biblioteca popular. Recientemente, fue remodelada para convertirse en el Centro Cultural de Purmamarca, en una clara orientación hacia 
el desarrollo del turismo. La primera escuela del lugar se creó en 1908. Este gran edificio no fue ubicado frente a la plaza, sino hacia el oeste, a unos 200 metros, en la parte alta del pueblo. Su construcción se distingue del resto de los edificios por la altura que posee (mayor al del resto de las construcciones) y por su imagen institucional con detalles de la arquitectura ferroviaria, en auge en el momento en que fue levantada. En los últimos años, un importante cambio en relación a los edificios públicos fue la construcción del colegio Bachillerato No 18 Profesor Héctor Cazón. Esta institución ya funcionaba desde finales de la década de 1980 dentro del predio de la escuela primaria. La obra fue inaugurada en 2007, en un predio contiguo a la escuela primaria, frente al cerro El Porito.

\section{El acceso vial}

Antiguamente, se accedía a Purmamarca, desde la ruta principal que provenía de la Quebrada de Humahuaca, a través del lecho del río homónimo. En 1974 se realizaron las primeras obras para el mejoramiento de la entonces RP 16, por la Quebrada de Purmamarca, para conectar a la ciudad de San Salvador de Jujuy con la zona puneña y el paso de Jama, en el límite con Chile (Ballatore, 2005). De todas formas, las comunicaciones con Purmamarca siguieron siendo dificultosas, ya que el camino era de ripio y sufría recurrentes derrumbes e interrupciones con las periódicas avenidas del río. Un hito de importancia en la historia de este poblado fue el acondicionamiento de esta ruta desde 1991, ya que fue asfaltada, protegida en las zonas de derrumbe e incorporada al sistema vial nacional, con el número 52 y al sistema continental dentro del Eje de Integración del Capricornio (Tomasi y Benedetti 2013). Esto trajo algunas consecuencias trascendentales para Purmamarca (Figura $N^{\circ} 7$ ):

- Desde ese momento, pasó a estar atravesada por un corredor vial internacional, actualmente denominado Eje de Integración y Desarrollo del Trópico de Capricornio.

- Por otro lado, aumentó considerablemente la circulación de vehículos por la zona. Pasó de tener un índice de tránsito medio diario anual de 350 vehículos en 1997, a otro de 1.100 en 2009 y de 1.320 en 2012 (Dirección Nacional de Vialidad).

- Además, se elevó el nivel de la ruta, tornándose una barrera para acceder al río desde la zona central del pueblo.

- También, ocurrió que el lugar se transformó en un hito en el camino a Chile, una posible parada de aprovisionamiento, especialmente para los visitantes que van camino hacia las Salinas Grandes y la Puna.

- Finalmente, a mediados de la década de 2000, cuando se elevó el nivel de la RN 52 en el tramo frente al pueblo, se modificó el acceso principal, a fin de que el nuevo camino no atravesase el viejo casco urbano. En el pasado, se hacía por un angosto camino de ripio, por la zona Ilamada el Bobal, que se desviaba de la ruta y desembocaba en la calle Salta, detrás de la iglesia. Hoy se ingresa al poblado desviándose de la RN 52, entrando por la Av. San Martín (Figura $N^{\circ} 8$ ).

\section{Nuevos recorridos peatonales y comerciales}

El núcleo histórico, en torno a la plaza, no tuvo cambios sustanciales en su traza durante el siglo XX, aunque sí existieron cambios relacionados con la movilidad de vehículos y personas durante la década de 1990 a raíz de las modificaciones realizadas en la RN 52, recién señaladas, y la peatonalización de determinadas calles. Entre los cambios primordiales se encuentran:

- En el pasado, la calle Salta y la calle Belgrano eran parte del recorrido casi obligatorio para los autos que ingresaban a Purmamarca. Allí, progresivamente, se fueron asentando los primeros comercios de venta de suvenires. Recientemente, la calle Belgrano, en el tramo lindero a la iglesia, fue empedrado, se pusieron escaleras para salvar los desniveles y se colocaron bancos, carteles, cestos de basura y artefactos de iluminación acompañando este nuevo paseo peatonal. En relación a esto último, la calle Salta, detrás de la iglesia, dejó de ser una de las principales vías de acceso perdiendo su preponderancia dentro del pueblo.

- En el presente, el recorrido que hacen los visitantes en automóvil dentro del casco urbano generó nuevos espacios de comer- 
Figura $\mathrm{N}^{\circ} 7$

RP 16 (antes de la década de 1970) y RN 52 en la actualidad
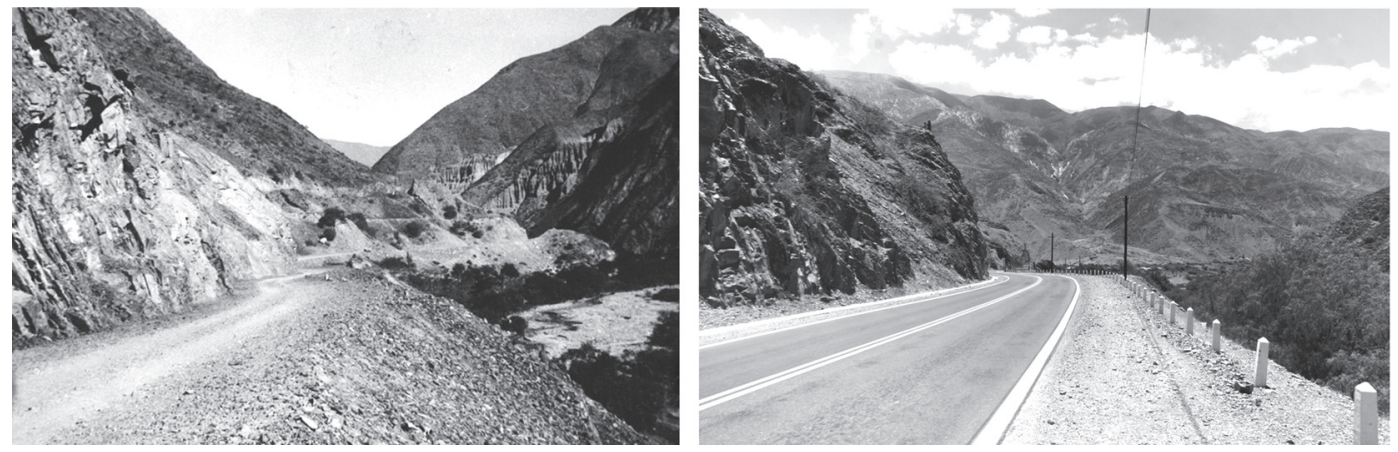

Fuentes: (Izquierda) Archivo General de la Nación/ RP 16 - sin fecha / (Derecha) RN 52, Tommei 2011.

Figura $\mathrm{N}^{\circ} 8$

Purmamarca. Planos en dos escalas con detalles sobre cambios en la traza urbana y fotografías de la calle peatonal, al costado de la capilla, donde se emplaza el algarrobo histórico. Década de 1970 y año 2011

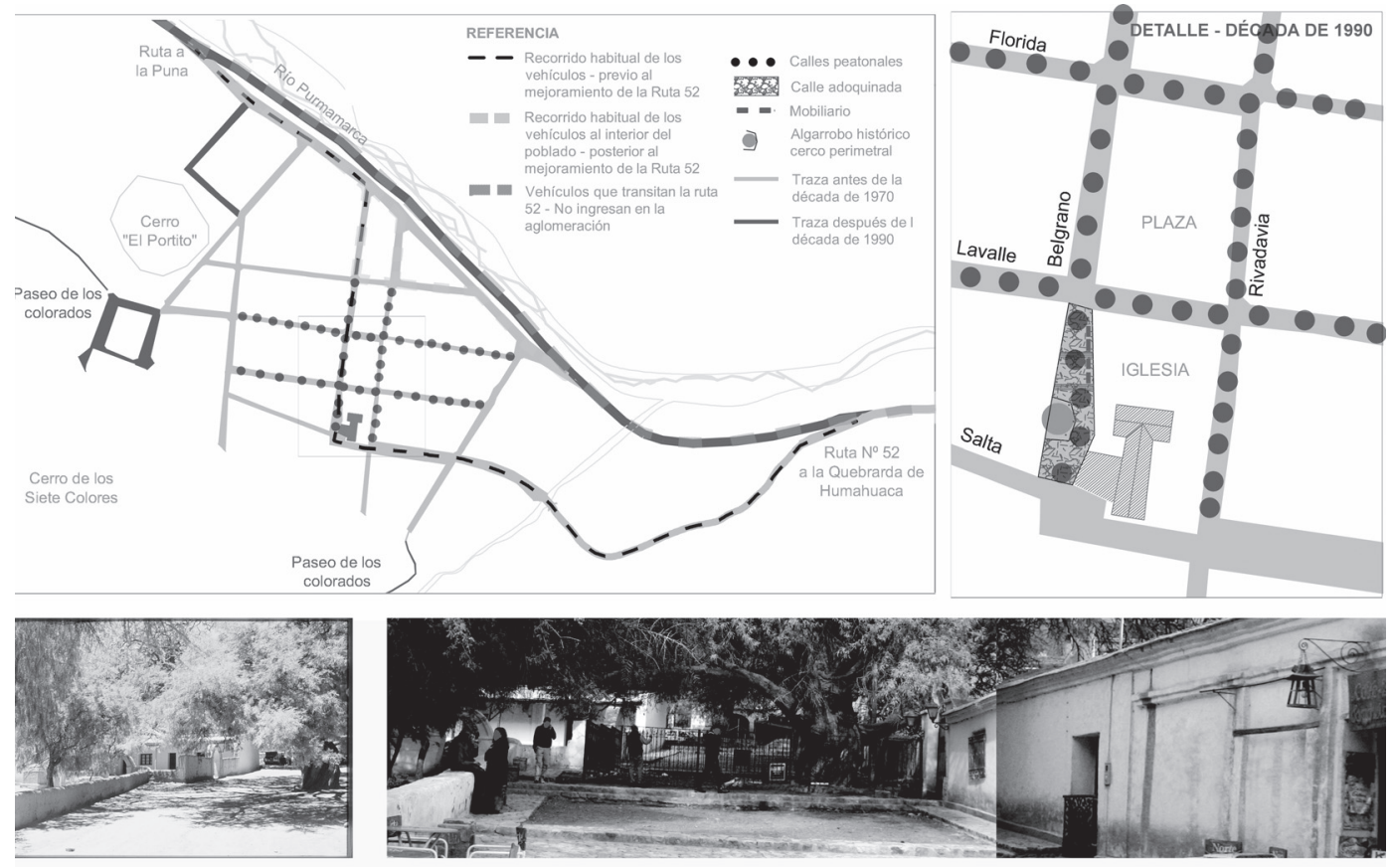

Fuente: Elaboración propia - Fotografías de Isabel Martínez de San Vicente, década de 1970 (entregada por la autora) y fotomontaje propio, mayo de 2011.

cio donde hay mayor circulación. Asimismo, el recorrido desde donde los micros dejan a los visitantes hasta la plaza se han implantado nuevos locales de venta de "regionales".
- El "algarrobo antiguo", un ícono turístico, que se encuentra sobre la calle Belgrano, fue enrejado. Las calles alrededor de la plaza también se hicieron peatonales, se amplió el área de puestos en la feria de 
la plaza, que hoy ocupa tres de los cuatro lados de la manzana, asignados por la Comisión Municipal. En la vereda que está frente a la capilla no se permite la instalación de puestos. Esta situación obliga a los vehículos a desviarse y a los visitantes a transitar este espacio a pie (Figura $\mathrm{N}^{\circ} 8$ ).

- Mediante Ordenanza Municipal (007/2009), desde 2009 se estableció una zona peatonal en algunas calles internas del pueblo (calle Lavalle, en toda su extensión; Rivadavia y Belgrano desde Salta hasta Libertad, Florida desde Gorriti a Sarmiento) y deja prohibida la circulación y permanencia de vehículos en los tramos de calles que rodean la plaza del pueblo. Además establece las vías de circunvalación para automóviles, camionetas y ciclomotores (por el acceso antiguo y las calles Salta, Sarmiento, Pantaleón Cruz, Gorriti y la Av. San Martin) y el sector para el transporte de pasajeros (en el triángulo formado por los tramos de las calles Libertad, Rivadavia y Av. San Martin), entre otros detalles que regula esta ordenanza. Si bien no se ve en el pueblo que esta norma se cumpla en su totalidad, las calles peatonales y los lugares y acceso de los servicios de pasajeros se utilizan como tales ${ }^{7}$.

Hemos identificado y analizado cinco cambios en la traza histórica, acontecidos en los últimos años: (1) se opacó la importancia que tenía la iglesia debido a la incorporación de nuevos edificios y a la remodelación de viejas construcciones que estaban a su alrededor (2) se amplió la traza en nuevas direcciones, quebrando la ortogonalidad que poseía y superando algunos límites preexistentes (3) se construyó el nuevo edificio de la escuela secundaria, con nuevos métodos constructivos y un diseño arquitectónico que se diferencia notablemente de las viejas construcciones (4) se mejoró notoriamente la vía de ingreso al pueblo, cambiando el punto de acceso, las visuales y aumentando el tránsito turístico y de mercancías que pasan por allí y, por último, (5) se peatonalizaron algunas calles y se generaron nuevas zonas de comer-

\footnotetext{
7 Las calles peatonales no tienen, en apariencia, la extensión exacta que la ordenanza indica.
}

cios para los turistas, preestableciéndose, así, distintos modos de transitar el pueblo.

\section{Usos del suelo vinculados a la demanda turística}

Uno de los cambios más notables vinculados a la turistificación se relaciona con los usos del suelo. Algunas descripciones sobre Purmamarca dan cuenta de una población agrícola que ocupaba los terrenos ubicados sobre el río homónimo para producción de autoconsumo con magros márgenes para intercambiar (Cf. Daniel Cerri, Informe incluido en: Ministerio del Interior, 1900:430-431; Vignale, 1948:19; Coní, 1951:339). Pero la agricultura no se practicaba solamente en zonas lejanas: la aglomeración era un ámbito de residencia y producción. Hasta la década de 1990 la mayoría de los lotes incluían la vivienda familiar, una extensión variable de terrenos para cultivo de hortalizas, frutas o flores, un corral para animales y, en algunos casos, el agregado de un local que funcionaba como proveeduría. Durante la década de 2000 se observa una aceleración en el cambio de funciones, orientada al sector de servicios turísticos, y que presentamos en la figura $N^{\circ} 9$ bajo la categoría genérica servicios turísticos:

- Hospedaje. En 1997, la mayoría de los turistas no permanecían en el poblado más que unas horas (Chorolque, 1998), ya que solo el $16 \%$ se hospedaba en Purmamarca, en casas de familia no registradas y en campings sin servicios. De hecho, los alojamientos hasta la década de 1990 eran solo algunas casas de familia no registradas. Una década después la situación cambió significativamente. El primer establecimiento hotelero inaugurado en esta localidad lo hizo en el año 2001. Según un relevamiento propio e información facilitada por la Secretaría de Turismo y Cultura de la Provincia, en 2009 había 26 edificaciones hoteleras registradas, 18 ubicadas en el casco histórico y siete en las afueras, sobre la RN 52. Los hoteles más alejados, son los de mayor categoría, con las tarifas más altas del lugar. Se caracterizan por poseer terrenos amplios transformados en jardines. En varios casos poseen piscina, restaurante propio y un local de venta de souvenires. A esa oferta 
se le suman los alojamientos en casas de familia -no registrados- y los cuatro campings -que abren únicamente en verano-, llegando a sumar alrededor de 66 establecimientos hoteleros (Porcaro y Tommei, 2012).

- Servicios gastronómicos. Vecinos del lugar recuerdan que alrededor de 1976 se instaló el primer restaurante. Anteriormente, existieron solo comedores esporádicos que abrían para ocasiones puntuales por unos días. En 1998, solo existían cuatro lugares que ofrecían un servicio gastronómico (Chorolque, 1998). Según relevamientos propios, en 2009 ya eran 17. A esta cuantía se deben sumar los restaurantes pertenecientes a los hoteles que se encuentran en las afueras del casco histórico. Algunos locales se ofrecen como restaurantes y otros como cafés y bar o resto bar. La gran mayoría de estos establecimientos están enteramente destinados a los turistas.

- Venta de souvenires. Con el nombre de regionales, en Purmamarca se conoce a los locales dedicados a la venta de souvenires. En 1964 Nicolini identificó la existencia de algunos almacenes en las zonas bajas del pueblo (Nicolini, 1964:30). En 1991, las casas con comercios -sin especificar si son de venta de souvenires y/o mercados- eran aproximadamente 15 (Rotondaro, 2001). Varios pobladores mayores informan que en la década de 1970, cuando comenzó a registrarse el ingreso regular de turistas, se abrieron los primeros regionales, ubicados en las calles de mayor circulación vehicular. En 1998 Chorolque (1998) calculó que había entre 18 y 20 puestos de venta de artesanías, sumando los locales y los puestos en la plaza, que aumentaban a 50 en julio, mo-

Figura $\mathrm{N}^{\circ} 9$

Pueblo de Purmamarca. Usos del suelo. Año 2011

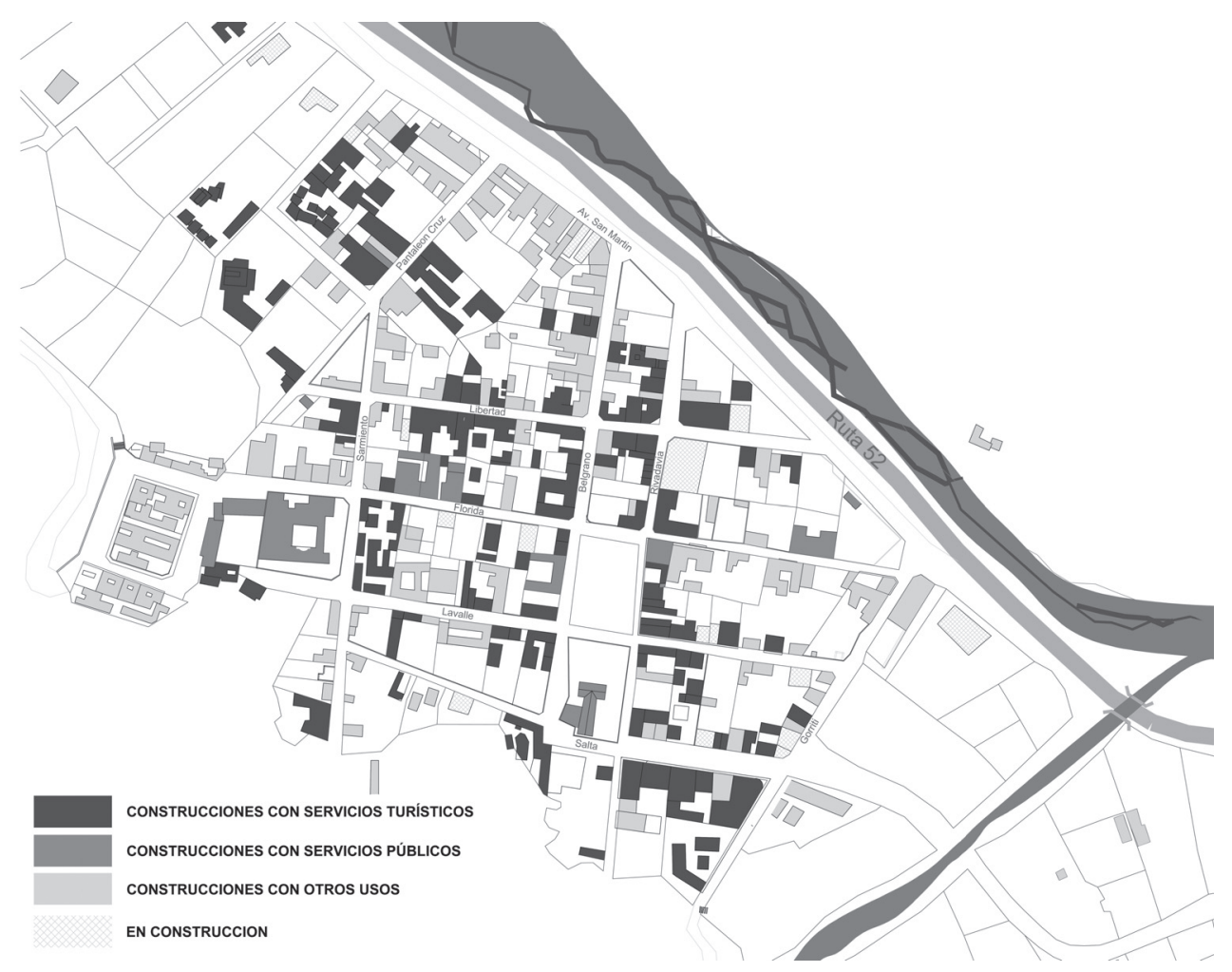

Fuente: Elaboración propia en base a un relevamiento propio, 2009 y 2011, al catastro de Jujuy, 2009 e imagen satelital Google Earth, 2007. 
mento de temporada alta. En el año 2009 contabilizamos, en temporada baja, 84 lugares de venta de regionales, 32 locales comerciales de regionales y 52 puestos de venta en la feria; sin contar aquellos puestos ubicados en puntos de la vía pública turísticamente estratégicos, como acceso al pueblo, el acceso al mirador El Porito, cerca de La Terminal, en los accesos del Camino de los Colorados, ente otros.

En síntesis, a lo largo de la década de 2000 se produjo un cambio notable en los usos del suelo. Parcelas que durante décadas, tal vez siglos, fueron utilizadas para usos agropastoriles y residenciales, se reorientaron por completo hacia la actividad turística.

El Artículo $5^{\circ}$ de la Ordenanza Municipal 006 de 1971 declaraba: "Se mantendrá en todo el conglomerado urbano el carácter de ciudad-huerta, para el cual el factor de ocupación del suelo no será superior al 20\%". La "ciudad-huerta" de la década de 1970, donde la mayoría de las viviendas tenían su anexo con cultivos y/o corrales con animales, desde inicios de la década de 2000 fue siendo reemplazada por la que podríamos denominar "ciudad-turística", en donde una importe porción de las construcciones están destinadas a brindar algún tipo de servicio a los turistas. Mientras que antes las huertas y corrales anexos a la vivienda se encontraban en la parte trasera del lote, ahora, en la mayoría de los casos, las áreas comerciales pasaron a ocupar el frente de las viviendas, abriéndose hacia la calle, desplazando el espacio dormitorio hacia el fondo del lote.

\section{Cambios en la estética de las construcciones}

Así como Humahuaca está identificada como el "corazón de la Quebrada" y Tilcara es conocida como "Capital Arqueológica" (Sitio Nortenet), actualmente Purmamarca se describe como un pueblo boutique (Diario Página 12). Este mote da cuenta del importante cambio estético acaecido en el lugar.

Durante la década de 2000 la inversión y especulación vinculada a la activación turística, junto con la visible demanda de los visitantes, han generado un importante crecimiento constructivo. El 55\% de los patrones y socios son "de fuera de la Quebrada". Este grupo de empresarios ha tenido una inserción más exitosa que los emprendedores locales. Esto se debe, en gran parte, a que contaron con mayores facilidades crediticias que los quebradeños (Troncoso, 2009b). Justamente, los operadores de los servicios turísticos exigieron un tipo de arquitectura diferente a la tradicional del lugar, acordes a los usos de alojamiento, gastronómico o de venta de regionales. Algunos edificios fueron construidos a nuevo, mientras que otros, generalmente viviendas, fueron remodelados.

Tradicionalmente, las construcciones de viviendas eran pensadas, diseñadas y realizadas por los futuros usuarios junto a los maestros constructores. Se hacían con materiales del lugar, como por ejemplo distintas tierras y arcillas, arenas, gravas, piedras, vegetales, ramas y troncos, guano, tientos de cuero, caña hueca, entre otros. Entre las técnicas constructivas que se reconocen como tradicionales podemos mencionar el uso de piedra en bruto o seleccionada con mortero de barro para los cimientos. Para los muros se usaba en algunos casos la piedra apilada sin mezcla de unión (especialmente para cercos, corrales y otros fines). Asimismo, el muro de piedra con mortero fue usado en las viviendas. Pero, el más repetido dentro de la aglomeración, es el mampuesto de adobe hecho con tierras y agua del mismo sitio y muchas veces algún agregado (por ejemplo: paja amarilla). Estos muros portantes (sin estructura independiente), a veces eran revocados con barro y pintados con cal, solo a veces eran coloreados con cal mezclada con tierra del lugar. Los techos tradicionales eran construidos a una o a dos aguas. Se hacía con una estructura de sostén construida con tablas de cardón; con rollizos y caña tejida; con rollizos y ramas de arbustos y una cubierta con una torta de barro, de paja o de paja embarrada. Los pisos solían ser de tierra o de tierra apisonada; las aberturas eran de tamaño mínimo y no era tradición la construcción de galerías. Las casas-habitación tradicionales consisten en una sucesión de recintos de una sola planta volcadas hacia un patio central que las comunica, formando una $L$ o una $U$, donde predomina la ortogonalidad. Las casas en espacios urbanos se cerraban en todo el perímetro del lote. Si las construcciones no alcanzaban, se levantaba un muro que terminaba de cerrar el frente de 
la vivienda, de modo que las calles estaban delimitadas por la sumatoria de construcciones que separaban claramente el interior del exterior. Las viviendas se implantaban en solares, en los que además de la casa-habitación había una zona de influencia en donde se cultivaba y criaba animales (Nicolini, 1964a, 1964b, 1964c; Rotondaro, 2001; Nostro, 1990; para un mirada más amplia sobre la temática, Tomasi y Rivet 2011).

La mayor parte de los nuevos edificios y algunas remodelaciones de viejas construcciones fueron hechas por arquitectos formados en centros académicos urbanos del país. Los especialistas matriculados han creado en el lugar una nueva imagen arquitectónica y han incorporado nuevos materiales -ladrillos cerámicos huecos y ladrillos macizos, entre otros mampuestos, membranas asfálticas y nuevos tipos de aberturas-, nuevas técnicas constructivas -como las estructuras independientes con hormigón armado-y terminaciones en piedra o revocadas y pintadas con colores similares a la tierra-ocre, terracota-. Las nuevas construcciones, en su mayoría, hechas con estructura de hormigón independiente permiten amplios cerramientos con carpintería y muros de adobes u otro mampuesto no portantes, admitiendo que sean tabiques de menor espesor que las viejas construcciones de muros portantes. Además, hay muchas transformaciones en los diseños: se incorporaron formas curvas, se perdió el tramado ortogonal característico, los huecos se agrandaron y se acomodaron a los diferentes diseños -rectangulares, ventanas corridas, circulares, etcétera-, se incorporan cúpulas, balcones, terrazas y galerías, se hicieron pisos semienterrados y edificios de dos pisos. Además, no se construyó todo sobre la línea municipal sino que se han hecho retiros, por lo que la calle perdió el marco que las viviendas le generaban en el pasado, delimitando claramente el espacio de circulación (Figura №10).

Como consecuencia de estas nuevas técnicas constructivas e innovadores diseños, la vista de la obra nueva sin revocar tiene una terminación diferente a las construcciones preexistentes, poco atrayente a los visitantes (en donde la estructura independiente y de hormigón se resalta). Pero ello queda oculto con los revoques que se usan en la mayoría de las obras nuevas, en general revoques de barro con algún agregado -cal, cemento-, que le dan al material mayor resistencia a la erosión por lluvia y la resistencia a la rotura (Chiappero y Supisiche, 2006). Este revoque termina siendo pintado, para mejorar la "prolija desprolijidad en las terminaciones" diseñada (Tomasi, 2011:165).

Esta renovación edilicia y estética contribuyó a la generación de un formato boutique. La Real Academia Española define boutique (voz francesa) como: 1 . Tienda de ropa de moda; 2. Tienda de productos selectos. EI primer hotel boutique se estableció en Nueva York en la década de 1980 y desde entonces se difundió en el ámbito de la arquitectura y el diseño. Este tipo de emprendimientos, que no se restringe solo a la hotelería, se propone como algo personalizado, pequeño en relación a los tradicionales alojamientos, que logre diferenciarse estéticamente de las clásicas cadenas hoteleras, orientado a consumidores de ingresos medios y altos que buscan nuevas ofertas. A la hora de construirlos, las características de la zona en donde se implantan influyen en la fisonomía que tendrá el futuro hotel: se produce una suerte de fusión entre patrones locales y extralocales, tanto en el diseño como en el tipo de materiales que se emplea. Son hoteles generalmente lujosos o no convencionales $y$, en ocasiones, son emplazados en antiguas casas recicladas. Se diferencian de las grandes cadenas por ofrecer una clase de alojamiento, servicios e instalaciones excepcionales y personalizadas. Suelen ser pequeños, con menos de 30 habitaciones (Rosso, 2010).

En Purmamarca, cada día son más las construcciones que se adaptan a estas pautas. "El Marqués de Tojo. Hotel sin tiempo", emplazado dentro del casco histórico, es un buen ejemplo para comprender las características que poseen en esta localidad los hoteles del tipo boutique. Este establecimiento posee diez habitaciones. Además de alojamiento, ofrece un restaurante gourmet de comida regional, una cava de vinos, una zona para la degustación y una pileta climatizada. En su promoción, se destaca: "disfrute su estadía con las comodidades de un marqués". El diseño también responde a las características boutique. Por un lado, copia del entorno los volúmenes prismáticos y su cubierta inclina- 

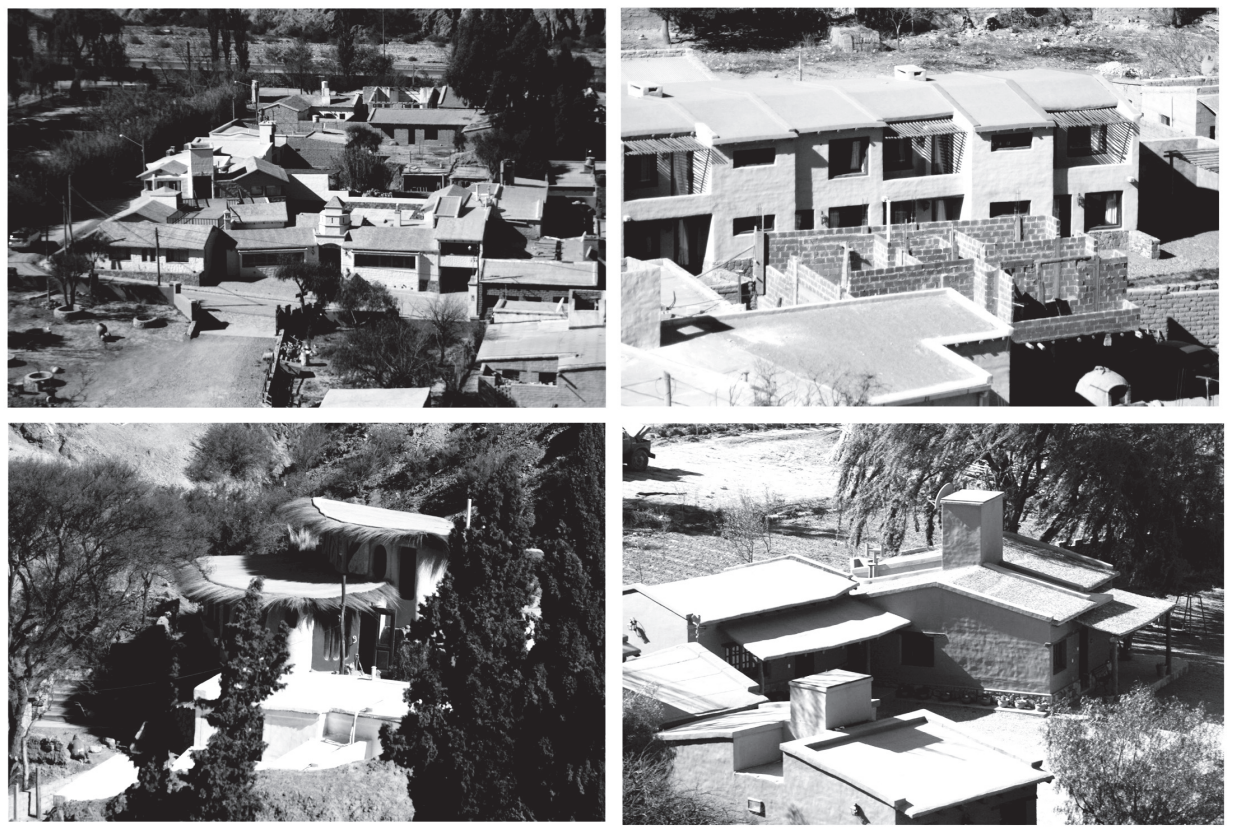

Fuente: Archivo personal de los autores, 2009.

da. Por otro lado, están semienterrados y son de doble altura, con ángulos caprichosos y no ortogonales, diferenciándose de la arquitectura del lugar. Utiliza algunos materiales de la zona (adobe y piedras), aunque, en general, con técnicas constructivas novedosas para el pueblo. Asimismo, incorpora materiales traídos desde otros lugares (particularmente esta obra fue concebida en varios espacios con ladrillo común visto). Es de resaltar que posee una cúpula en su entrada, la cual tiene poca relación con el lugar en el que se implanta el edifico. Como parte de su promoción, destaca que "conviven el diseño, confort y tecnología actuales en armonía con el arte de los últimos cuatro siglos" (Marqués de Tojo).

La estética boutique no se restringe a la hotelería. Los locales comerciales en Purmamarca también se están orientando en esa dirección: se abren grandes ventanas con paños fijos, con vidrieras hacia la calle, rompiendo los pesados muros que separaban el interior del exterior. Se cambiaron las pequeñas ventanas por amplios ventanales que invitan a mirar, entrar y comprar; como una gran boutique. La intimidad del espacio doméstico se transforma en escaparate (por razones de extensión del artículo no ampliaremos esta cuestión). Asimismo, se asiste a un incremento de marcas registradas, cambiando el carácter indiferenciado de los productos "regionales" por productos exclusivos "artesanales" con sello de categoría.

Los cambios reseñados han significado una nueva articulación entre el espacio público, el espacio privado (ámbito doméstico) y el espacio privado abierto al público. Mientras que en el pasado solo algunos pocos almacenes existentes eran los lugares de "intercambio y reunión" (Nicolini 1964b:30), en la actualidad muchas viviendas se reconvirtieron y anexaron espacios con infraestructura para el turismo o construyeron nuevas obras con servicios turísticos. Así, se incrementaron significativamente las áreas de uso común, que es un espacio que conecta y separan a la calle y a las viviendas. Se generaron algunos frentes de calle que por completo pasaron a estar compuestos por estos espacios comunes que si bien están cerrados por los muros, ven- 
tanas y puertas, poseen grandes ventanales -en muchos casos iluminados- y aberturas, pueden ser atravesados visualmente y físicamente por quienes están recorriendo el lugar.

Un establecimiento que ha sido concebido con una estética similar a la que poseen los nuevos hoteles boutique es la escuela secundaria (Figura $N^{\circ} 11$ ). Es una obra de arquitectura que, a pesar de usar algunas de las técnicas y los materiales del lugar, introduce importantes transformaciones tanto en los materiales, como en el diseño espacial y la estructura formal. La fachada fue diseñada retirada de la línea municipal, cediendo espacio en el frente al espacio público. Tiene terminaciones en revoque, pintado en color marrón. En otro sector, se eligió levantar el muro en toda su altura, realizado con piedras de colores y morfología diferentes al que se encuentra en su entorno inmediato. Asimismo, su particular forma de colocación aporta a que el resultado sea una textura y tonalidad diferente a la conocida en tiempos previos al boom turístico. Además, los ángulos de encuentro no son oblicuos y posee dos plantas en algunos sectores, entre otras características (Novick et al., 2011).

Podemos señalar, entonces, que un rasgo característico asociado al proceso de turistificación de Purmamarca fue la adaptación de buena parte del equipamiento de servicio a la estética y funcionalidad de tipo boutique, entendido como un patrón orientado a consumos para sectores urbanos de ingresos medio y alto.

Figura $N^{\circ} 11$

Purmamarca. Bachillerato, vista exterior e interior, año 2009
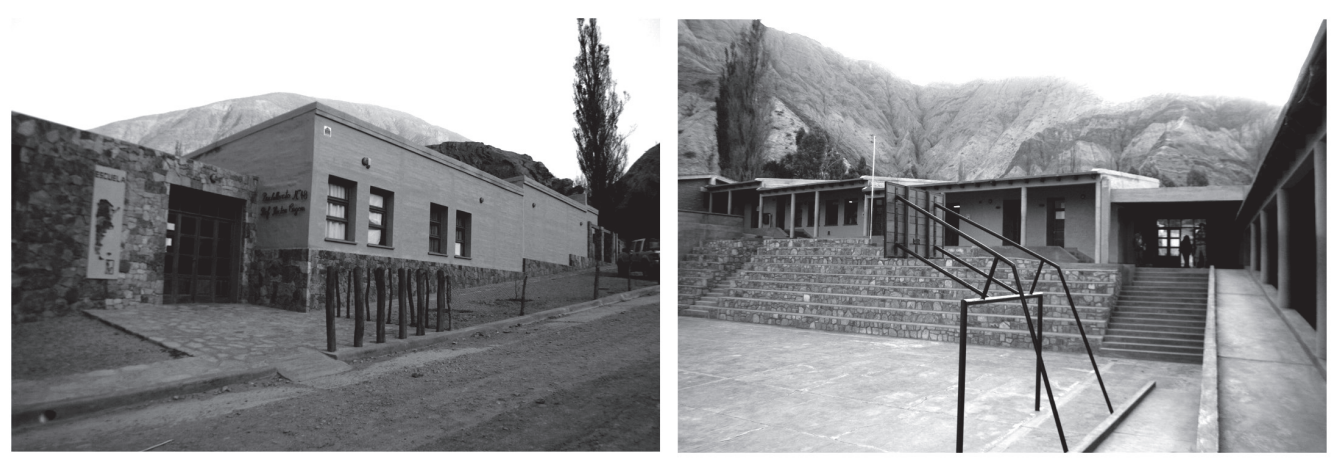

Fuente: Archivo personal de los autores, 2009.

\section{Surgimiento de un pueblo-dormitorio}

Purmamarca era un lugar que no estaba sometido a las reglas del mercado de tierras, el cual se activó en paralelo al desarrollo de la actividad turística local. Al mismo tiempo, atraídos por el mercado de trabajo en crecimiento, se incrementó la población residente. Por otra parte, se construyeron pocas viviendas nuevas -en relación a la demanda-, mientras que las existentes experimentaron un incremento en el precio de sus alquileres, cuando no se convertían en locales comerciales o restaurantes. Todo esto impulsó a que muchos habitantes participen en la toma de tierras para el trazado de una nueva aglome-

ración. Fue así que surgió, en el año 2003, la localidad o paraje de Chalala, emplazado en la Quebrada homónima, perpendicular a la de Purmamarca (Figura $N^{\circ} 4$ ).

Los "intrusos", como los llamó un diario provincial en ese momento, explicaron que su accionar se debía a la "imposibilidad de pagar los elevados alquileres que se cobran en la localidad turística" (Diario El Tribuno, 26 de octubre de 2003:19). Este nuevo paraje, formado en un principio por 59 familias, fue levantado en menos de una década por la Comunidad Indígena de Chalala, constituida como tal tras la toma de tierras (Figura $\mathrm{N}^{\circ}$ 12). A partir de charlas informales con habi- 
Chalala, vista panorámica seis años después de que comenzó a construirse.

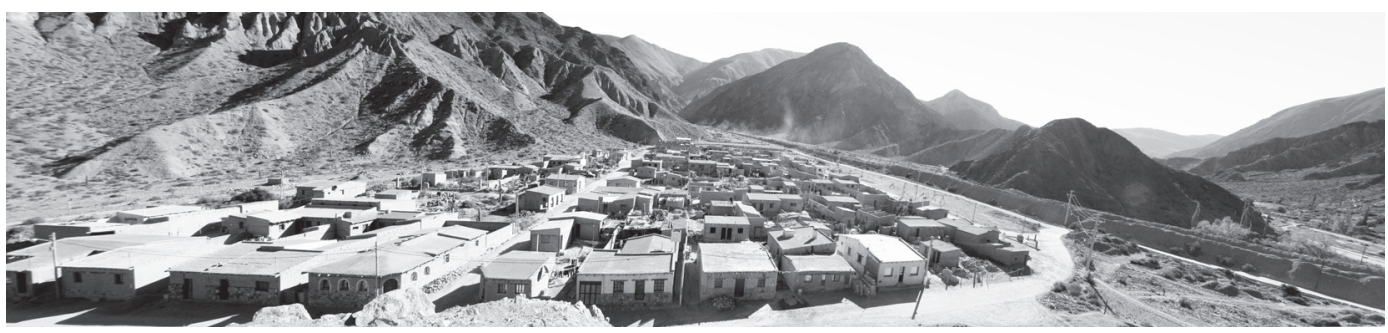

Fuente: fotomontaje propio, mayo 2009.

tantes actuales del paraje de Chalala se sabe que parte de esta comunidad ha inmigrado desde el campo al poblado en la década de 1980, junto a sus padres y familiares. Esto mismo lo confirmó un vecino de Purmamarca, quien explicó que las familias de la comunidad de Chalala son personas oriundas de este ejido (entrevista a un purmamarqueño que participó en la formación de Chalala, diciembre de 2011).

En un principio, realizaron la demarcación de manzanas, calles y lotes dejando, además, espacios para usos específicos (por ejemplo para la comisaría -que finalmente no se construyó, dando lugar a la salita y la biblioteca- y para un centro deportivo y/o educativo). Actualmente, constituye un pueblo consolidado, con una traza y una trama definida. La obtención de la infraestructura básica tuvo un largo proceso. En 2006, tres años después de la toma, obtuvieron el agua comunitaria $^{8}$. Luego consiguieron la energía eléctrica, que inicialmente también fue comunitaria. Por ser tierras comunitarias, para obtener que los servicios entren al pueblo tuvieron que ceder al Estado los terrenos donde se asientan las calles. El 29 de marzo de 2007 la Secretaría de Derechos Humanos les entregó el Título Comunitario de la tierra (Comunidad de Chalala 2010). En ese mismo acto se inauguró el alumbrado público y la red de energía de baja tensión (Diario Pregón, 2007). Obtuvieron en ese tiempo el agua potable. En los últimos años también se

\footnotetext{
8 Entrevista realizada a un integrante de la Comunidad de Chalala (mayo de 2011).
}

inauguró un Centro Integrador Comunitario (CIC) equipado con consultorios médicos, cocina y un salón de usos múltiples.

Desde los primeros años, la comunidad comenzó a identificarse con sus propias actividades culturales. Así, en 2005 se constituyó la Comparsa "Chala-chala" para los festejos del carnaval y se inauguró un monolito en el ingreso a la comunidad en homenaje a las familias pioneras, donde se izan las banderas argentina y la wiphala. En 2007 acordaron que la Virgen de Luján sería su Patrona. Ese mismo año pusieron nombre a las calles con las denominaciones de plantas típicas del lugar (Comunidad de Chalala 2010).

El surgimiento del pueblo de Chalala se puede comprender como un resultado del proceso de gentriticación acontecido en Purmamarca. Esta idea remite al proceso por el cual una zona es reconvertida y valorizada en el mercado inmobiliario, mediante operaciones políticas y sociales (zonificaciones, concesiones, subsidios, beneficios fiscales, etc.) que la ponen a disposición de la gentry (los "bien nacidos" o alta burguesía) (Navarro Floria y Vejsberg, 2009). La gentrificación también se puede relacionar a los imaginarios urbanos, en los que los cascos históricos degradados fueron recuperados y revalorizados por clases de mayor nivel adquisitivo que las que vivían en "tiempos degradados". Al mismo tiempo, y articulado a estos hechos, se estudian los desplazamientos hacia la periferia "en busca de fantasías y utopías" además de soluciones habitacionales (Hiernaux y Lindón 2006:115). Lo que ocurrió en Purmamarca puede aproximarse a esta idea: era un lugar que no estaba sometido a las reglas del mer- 
cado de tierras, el cual se activó con la turistificación del lugar. Los sectores con menores ingresos del lugar, y con menor conocimiento del mercado inmobiliario y turístico y mayores dificultades para adquirir créditos comenzaron a tener dificultad para acceder al suelo urbano, frente a la competencia de empresas con capital suficiente para afrontar los costos inmobiliarios. Por lo anterior, se vieron obligados a tomar tierras en zonas alejadas del centro histórico. La aglomeración de Chalala aún no cuenta con escuela, oficinas gubernamentales, entre otros servicios, ni fuentes de trabajo in situ, razones por las cuales todavía se encuentra en total dependencia de Purmamarca, permaneciendo como "pueblodormitorio".

Vale la pena aclarar que, además de Chalala, se ha realizado un nuevo loteo a aproximadamente cuatro kilómetros de Purmamarca, en el cruce de la RN9 y la RN52. Comunidad Aborigen Coquena y un grupo de los vecinos de Purmamarca llevan años reclamando tierras para vivir, y finalmente en el 2011, según relata el periódico Lea, un propietario purmamarqueño donó parte de sus tierras al municipio de Purmamarca para que este pueda dar cauce a los problemas de tierras existentes. Ya se ha realizado el loteo del terreno y ya se han comenzado a levantar algunas viviendas. Se trata de un proceso similar al de Chalala, con el surgimiento de un nuevo "pueblo-dormitorio", también dependiente de Purmamarca9.

\section{Conclusiones}

A partir del año 2000 se aceleró la turistificación de Purmamarca: un pueblo agropastoril que atraía por el lapso de algunas horas (o inclusive menos) a algunos contingentes de visitantes que pasaban por allí en excursión, se convirtió en un pueblo boutique que atrae a turistas, tanto de alto poder adquisitivo como de bajo presupuesto (mochileros), de la Argentina y del extranjero, quienes permanecen allí por algunos días (o inclusive más). La oferta hotelera, gastronómica y comercial se

\footnotetext{
9 Por cuestiones de espacio no podremos explicar más de este nuevo asentamiento surgido hace apenas unos años.
}

amplió notablemente, orientada enteramente a los visitantes. La activación de Purmamarca como atractivo turístico no responde solamente al aumento en el número de hoteles y restaurantes, sino también a ciertos procesos culturales en el plano simbólico que pusieron en valor al destino turístico. El proceso de transformación material de Purmamarca, en relación a la prestación de servicios hoteleros, gastronómicos y comerciales, es considerablemente reciente -no supera las dos décadas- y llevó a catapultar a este lugar como destino regional, nacional e internacional para actividades recreativas y de ocio.

En forma sumaria, podemos resaltar las siguientes transformaciones:

- Se acondicionó la infraestructura carretera para soportar tránsito pesado, lo que mejoró la accesibilidad a la vez que llevó a la necesidad de cambiar las vías de acceso al casco urbano. Asimismo, se realizaron cambios en la traza para organizar la creciente circulación vehicular por el lugar. En una aglomeración de pequeñas dimensiones, pero con gran tránsito vehicular, algunos tramos se destinaron al uso exclusivo peatonal, promoviendo nuevos recorridos vehiculares. También, se protegieron con rejas elementos patrimonializados -como el "algarrobo histórico"- y se incorporó mobiliario para los visitantes -bancos, luminaria, etcétera- en las áreas peatonalizadas.

- Entre 1991 y 2009 se expandió y densificó el espacio construido. La densificación se produjo en los lotes del casco histórico, lo que llevó a la casi desaparición de las parcelas para cultivo y cría de animales que existían en la zona urbana y lo caracterizaba como pueblo-huerta. Asimismo, las barreras físicas a la expansión edilicia llevaron a que se ocuparan terrenos linderos a la ruta y sobre la quebrada de Chalala, transversal a la de Purmamarca, espacio que con el mejoramiento del sistema carretero posee actualmente un acceso privilegiado. Además, Chalala se transformó, ante la demanda insatisfecha de habitaciones por parte de la nueva población laboral atraída por los hoteles, en un pueblo-dormitorio.

- Se introdujeron nuevas técnicas y diseños arquitectónicos. Las técnicas tradicionales 
de autoconstrucción fueron desplazadas en parte por otras nuevas, traídas por arquitectos profesionales, quienes introdujeron el concepto boutique. Se comenzó a realizar obras diseñadas desde el conocimiento académico, pero buscando que se "mimeticen" a la zona, tanto en la forma como con los materiales. Esa tendencia no se restringió a la hotelería: servicios gastronómicos, locales comerciales y hasta la nueva escuela secundaria se sumaron a estas propuestas de diseño y servicio que plantea el rescate de lo local, desde una moda cuya lógica es global. Es esto lo que nos llevó a definir a Purmamarca, en la actualidad, como un pueblo boutique.

\section{Referencias bibliográficas}

ABÁN, L. Antiguos pueblos del norte jujeño y ex Territorio Nacional de los Andes. San Salvador de Jujuy: Talleres gráficos Gutemberg, 1990.

BALLATORE, I. Jama. La causa que movió montañas. Buenos Aires: Ed. PGA, 2005.

BENEDETTI, A. Les effets de I'incorporation. Transformations territoriales et réorganisation de I'habitat à Jujuy, République d'Argentine, durant le XXe siècle. Storia delle Alpi, 2003, N ${ }^{\circ} 8$, p. 99-122.

BENEDETTI, A. Los secretos de la montaña. Minería y geografía histórica del Territorio de los Andes (1900-1943). Estudios Sociales del NOA, 2006, Nº 9, p. 5-48.

BERTONCELLO, R. Presentación. En: BERTONCELLO, R. (compilador). Turismo y geografía. Lugares y patrimonio natural-cultural de la Argentina. Buenos Aires: Ediciones Ciccus, 2008, p. 5-16.

BERTRAND, A. Memoria sobre las cordilleras del desierto de Atacama y regiones limítrofes. Santiago de Chile: Imprenta Nacional, 1885.

BURGOS, D. R. Conozca Jujuy. Sus glorias, paisajes, tradiciones, leyendas. Guía para el comerciante, Escolar, Profesional, Tu- rista y Público en general. 1960, Año 1, №1, p. 46

CHIAPPERO, R. y SUPISICHE, M. C. Arquitectura en tierra cruda. Breves consideraciones sobre la conservación y restauración. Buenos Aires: Nobuko, 2006.

CHOROLQUE, Z. M. Diagnóstico y análisis crítico de la realidad socio-económicoambiental del municipio de Purmamarca. Propuesta de Desarrollo. Tesis para optar al título de Licenciado. Jujuy: Facultad de Ciencias Naturales de la Universidad de Salta, 1998.

COMUNIDAD DE CHALALA. Informe entregado por una vecina purmamarqueña. Chalala: s/e, 2010

CONÍ, F. Diccionario Geográfico Argentino (1877-1880). Buenos Aires: Imprenta Coní, 1951.

DIARIO EL TRIBUNO. 59 familias de Purmamarca no tienen un lugar para vivir, 26 de octubre de 2003. Jujuy: Diario El Tribuno, 2003.

DIARIO PREGÓN. Decreto de tierras, red de baja tensión y alumbrado público para Chalala, 25 de enero de 2007. Jujuy: Diario Pregón, 2007. Disponible en Internet: http://www.pregon.com.ar/vernoticia. asp?id=70566\# ref70566.

DIRECCIÓN NACIONAL DE VIALIDAD. Información sobre Tránsito Medio Diario Anual. Disponible en linternet: http://www. vialidad.gov.ar/

DOCUMENTOS DE ARTE ARGENTINO. De Uquía a Jujuy. Cuaderno II. Buenos Aires: Academia Nacional de Bellas Artes, 1939.

DOCUMENTOS DE ARTE ARGENTINO. Por la ruta de los Inkas y en la Quebrada de Humahuaca. Cuaderno III. Buenos Aires: Academia Nacional de Bellas Artes, 1940.

FIDALGO, A. Breves Toponimia y Vocabulario Jujeño. Buenos Aires: La Rosa Blindada, 1965, p. 60. 
GUZMÁN, F. Memorias del paisaje. Microtoponimia de la Quebrada de Purmamarca. Jujuy. San Salvador de Jujuy: Universidad Nacional de Jujuy. 2004.

HIERNAUX, D. y LINDÓN, A. Geografía Urbana: una mirada desde América Latina. En: HIERNAUX, D. y LINDÓN, A. Tratado de Geografía humana. Madrid: Anthropos, 2006, p. 84-94.

INSTITUTO NACIONAL DE ESTADÍSTICAS Y CENSOS (INDEC). Censos de Población. Disponible en internet: http://www. indec.gov.ar/

JUJUY. Quebrada de Humahuaca. Un Itinerario Cultural de 10. 000 Años. Propuesta para la Inscripción a la Lista de Patrimonio Mundial de la UNESCO. Jujuy: Talleres Gráficos de Imprenta Zissi, 2002.

MARQUÉS DE TOJO. Disponible en internet: http://www.marquesdetojo.com.ar/index. html

MINISTERIO DEL INTERIOR. Memoria del departamento del Interior Correspondiente al año 1899. Tomo II-Anexos. Buenos Aires: TaIler Tipográfico de la Penitenciaría Nacional, 1900.

NAVARRO, P. y VEJSBERG, L. El proyecto turístico Barilochense antes de Bustillo. Entre la prehistoria del Parque Nacional Nahuel Huapi y el desarrollo local". Estudios y Perspectivas en Turismo, 2009, Vol. 18, p. 414433.

NICOLINI, A. El poblado y la iglesia de Purmamarca. Revista Nuestra arquitectura, 1964a, No 412, p 29-36.

NICOLINI, A. El poblado y la iglesia de Purmamarca. Revista Nuestra arquitectura, 1964b, No 413, p. 27-34.

NICOLINI, A. El poblado y la iglesia de Purmamarca. Revista Nuestra arquitectura, 1964c, No 414, p. 39-48.

NICOLINI, A. Pueblo de indios en el noroeste argentino. En: GUTIÉRREZ, R. (coordinador). Pueblo de indios, otro urbanismo en la región andina. Buenos Aires: ediciones Abya-yala, 1993, p. 381-447.

NORTENET. Disponible en internet: http:// www. nortenet.com.ar/Quebrada-de-Humahuaca-Jujuy.php

NOSTRO, M. El uso del espacio en cuatro viviendas construidas por un P. V. P. en Yacoraite, provincia de Jujuy. En: BERBEGLIA, C. (coordinador) Propuestas para una Antropología Argentina. Buenos Aires: Biblos, 1990, p. 47-72.

NOVICK, A.; FAVELUKES, G.; CATENAZZI, A.; CAÑELLAS, E.; MANCINI, C.; TOMMEI, C.; POTOCKO, A. y VECSILR, L. Las transformaciones del territorio. Mapas, patrimonio y lugares de la Quebrada de Humahuaca. Crítica, 2011, No 169, p. 1-46.

PÁGINA 12. Rutas Argentinas, 27 de agosto de 2007. Jujuy: Página 12, 2007. Disponible em internet: http://www.pagina 12 .com.ar/diario/suplementos/libros/10-2211-2006-08-27.html

PALEARI, A. Diccionario toponímico jujeño. San Salvador de Jujuy: Imprenta del Estado de la Provincia de Jujuy [1981] 1993.

PERIÓDICO LEA. Purmamarca, 5 de mayo de 2011. Jujuy: Periódico Lea, 2011. Disponible en internet: http://www.periodicolea.com/ index/item,6255/seccion,20/subseccion,38/ titulo, inauguraron-un-spa-y-festejaron-diezanos-del-primer-emprendimiento-turistico

PORCARO, T. y TOMMEI, C. Alojarse en Purmamarca, Jujuy. Acciones privadas en la construcción de un destino turístico. En: Jornadas internacionales patrimonio y cultura urbana, realizado en Rosario el 13 y 14 de septiembre, 2012.

RÖSSLER, M. Los paisajes culturales y la Convención del Patrimonio Mundial Cultural y Natural: resultados de reuniones temáticas previas. En: MÚJICA BARRERA, E. (editor). Paisajes Culturales en los Andes. Memoria Narrativa, Casos de Estudio, Conclusiones y Recomendaciones de la Reunión de Expertos. Lima: UNESCO, 1998. Disponible en Internet: http://www.condesan.org/unesco/ Cap\%2006\%20metchild\%20rossler.pdf 
ROSSO, A. Análisis de viabilidad de un negocio inmobiliario en el barrio de Retiro. Tesina Entrepreneurship. Buenos Aires: Universidad de CEMA, 2010.

ROTONDARO, R. Arquitectura y de Tecnología Constructiva en la Quebrada de Humahuaca. Transformación de los patrones tradicionales e impacto cultural. Buenos Aires: República de la Argentina, 2001.

SÁNCHEZ DE BUSTAMANTE, T. El camino a Bolivia por la Quebrada de Humahuaca. Contribución a su estudio. Buenos Aires: Tercer Congreso Nacional de Vialidad, 1937.

SECRETARÍA DE TURISMO Y CULTURA DE LA PROVINCIA DE JUJUY. Disponible en Internet: http://www.turismo.jujuy.gov.ar

SICA, G. Del pukara al pueblo de indios. La sociedad indígena colonial en Jujuy, Gobernación de Tucumán, siglo XVII. Tesis de Doctorado. Sevilla: Universidad de Sevilla, 2006.

TOMASI, J. ¿La revalorización de lo tradicional o la puesta en orden de lo local? En: NOVICK, A.; NÚÑ̃EZ, T. y SABATÉ BEL, J. (directores). Miradas desde la Quebrada de $\mathrm{Hu}$ mahuaca. Territorios, proyectos y patrimonio. Buenos Aires: Cuentahilos, 2011, p. 163-169.

TOMASI, J. y BENEDETTI, A. Territorialidades multiescalares. El Paso de Jama y el eje de capricornio, vistos desde un pueblo de pastores puneños (Susques, Jujuy, Argentina). En: NICOLETTI, M. y NÚÑ̃EZ, P. (compiladores). Araucanía - Norpatagonia: la territorialidad en debate. Perspectivas ambientales, culturales, sociales, políticas y económicas. San Carlos de Bariloche: IIDyPCa, 2013, p. 14-29.

TOMASI, J. y RIVET, C. (coordinador). Puna y arquitectura: las formas locales de construcción. Buenos Aires: Centro de Documentación de Arte y Arquitectura Latinoamericana-CEDODAL, 2011.

TOMMEI, C. y BENEDETTI, A. Purmamarca y su belleza policromática. Fotografía y descripción geográfica en la construcción de los lugares. Revista Párrafos Geográficos, 2012, Vol. 11, N² 2, p. 39-76.

TRONCOSO, C. Patrimonio y redefinición de un lugar turístico. La Quebrada de Humahuaca, provincia de Jujuy, Argentina. Estudios y perspectivas en turismo, 2009a, Vol. 18, p. 144-160.

TRONCOSO, C. Turismo y alternativas laborales: convivencias y desavenencias en la definición de la Quebrada de Humahuaca como lugar turístico. X Jornadas Argentinas de Estudios de Población. Realizado en San Fernando del Valle de Catamarca el 4, 5 y 6 de noviembre de 2009 b.

TRONCOSO, C. Patrimonio, turismo y lugar: selecciones, actores y lecturas en torno a la Quebrada de Humahuaca (Jujuy, Argentina) como patrimonio de la humanidad. Cuadernos de Turismo, 2010, № 25, p. 207-227.

VIGNALE DE ARDISSONE, L. Una señalada en Purmamarca. Revista Geográfica Americana, 1948, Año 15, 28/172, p.17-24. 
